\title{
Comunicação
}

[Communication]

\section{Padrão de deslocamento de bovinos Nelore em sistemas integrados de produção agropecuária}

\author{
[Displacement patterns of Nellore cattle in integrated crop livestock system]
}

E.A.R. Santana 1 , C. Andrighetto ${ }^{2}$, G.P. Mateus 3 , A.S. Aranha1, G.C. Lupatini ${ }^{2}$, P.R.L. Meirelles ${ }^{1}$, H.S. Aranha ${ }^{2}$, J.M.F. Santos ${ }^{2}$, P.A.C. Luz ${ }^{1}$, G.A. Trivelin ${ }^{2}$

\author{
${ }^{1}$ Universidade Estadual Paulista (Unesp) - Botucatu, SP \\ ${ }^{2}$ Universidade Estadual Paulista (Unesp) - Dracena, SP \\ ${ }^{3}$ Agência Paulista de Tecnologia dos Agronegócios - Andradina, SP
}

O sistema de integração lavoura-pecuáriafloresta (ILPF) é considerado atualmente inovador no Brasil (Balbino et al., 2012). Esse modelo integra os componentes agrícola, pecuário e florestal em rotação, consórcio ou sucessão, na mesma área (Balbino et al., 2011), ou seja, possui ainda o componente arbóreo que o diferencia da integração lavoura-pecuária (ILP). Poucos estudos mostram como as árvores afetam o comportamento dos bovinos, sendo a maior parte deles relacionados ao impacto das árvores para melhorar o conforto térmico (Navarini et al., 2009; Souza et al., 2010, Oliveira et al., 2011), que provocará alterações no comportamento animal.

Informações sobre a influência das árvores e dos seus arranjos sobre a exploração do piquete pelos animais e como influenciam os locais que os animais permanecem no piquete durante o dia são escassas. Por esse motivo, o objetivo do presente estudo foi caracterizar o padrão de deslocamento de bovinos de corte em áreas com sistemas integrados de produção agropecuária por novilhos da raça Nelore no noroeste do estado de São Paulo. Este estudo foi executado sob aprovação do Comitê de Ética para o Uso de Animais (Ceua), com protocolo número 86/2014.

O estudo foi conduzido no mês de agosto de 2015 , nas coordenadas geográficas $20^{\circ} 53^{\prime} 38^{\prime \prime}$ de latitude sul, $51^{\circ} 23^{\prime} 1$ ' de longitude oeste e $400 \mathrm{~m}$ de altitude. O clima predominante na região é o Aw, segundo Köppen. Os dados climáticos da área experimental foram coletados em estação meteorológica, localizada cerca de $2 \mathrm{~km}$ do local do experimento.

Os tratamentos corresponderam a três sistemas de produção: integração lavoura-pecuária (ILP); integração lavoura-pecuária-floresta (ILPF-1), com árvores de eucalipto plantadas em linhas simples, com distâncias entre linhas de 17 a $21 \mathrm{~m}$ e $2 \mathrm{~m}$ entre plantas e densidade de 196 árvores ha ${ }^{-}$ 1; integração lavoura-pecuária-floresta (ILPF-2), com árvores de eucalipto plantadas em linhas triplas, com distâncias entre linhas, plantas e renques de 3,2 e 17 a $21 \mathrm{~m}$, respectivamente, e densidade de 448 árvores ha ${ }^{-1}$. Nos dois sistemas ILPFs, foi utilizado o Eucalyptus urograndis (clone I-224). Foram avaliados três piquetes, sendo um de cada tratamento, com área aproximada de 2 ha cada.

O método de pastejo adotado foi de lotação contínua, com taxa de lotação variável, pela técnica de put and take (Mott e Lucas, 1952). Em cada piquete, foram utilizados três animais "testers" e um número variável de reguladores, conforme a necessidade de ajuste da taxa de lotação para manutenção da meta de manejo, com altura média do relvado de $30 \mathrm{~cm}$. A avaliação da altura era realizada quinzenalmente por meio de régua graduada e, na ocasião do presente estudo, o dossel forrageiro apresentou altura média de 30,27 e $29 \mathrm{~cm}$ para os sistemas ILP, ILPF-1 e ILPF-2, respectivamente (erropadrão da média $=0,44)$. Para as avaliações do experimento, utilizaram-se nove novilhos contemporâneos da raça Nelore de aproximadamente 24 meses ( \pm dois meses).

Recebido em 7 de março de 2017

Aceito em 15 de agosto de 2018

E-mail: erikellysantana@hotmail.com 
A mensuração da massa seca total de forragem (MST) foi realizada por meio de corte de todo material presente no interior de uma moldura com medidas de 1 x $0,5 \mathrm{~m}\left(0,5 \mathrm{~m}^{2}\right)$ em nove pontos de amostragem em cada piquete, em locais representativos das condições médias do pasto. A forragem cortada foi pesada, homogeneizada, e posteriormente foi retirada subamostra. Essas subamostras foram pesadas e levadas à estufa de circulação de ar forçada, para determinação da matéria parcialmente seca a $65^{\circ} \mathrm{C}$ até atingir peso constante. Após a secagem, as amostras foram novamente pesadas para determinação da MST, sendo encontrados os valores de 7960, 7412 e $5858 \mathrm{~kg} \mathrm{ha}^{-1}$ nos sistemas ILP, ILPF-1 e ILPF-2, respectivamente (erropadrão da média $=468 \mathrm{~kg} \mathrm{ha}^{-1}$ ).

Imagens via satélite da área experimental foram obtidas por meio do Google Earth, as quais permitiram a visualização dos renques de árvores, curvas de nível e demais referências locais de cada piquete. Juntamente às imagens, os croquis das divisões da área permitiram que fossem elaborados mapas dos piquetes (um de cada tratamento), nos quais seus limites, curvas de nível, árvores, bebedouros e cochos de sal fossem representados em sua devida localização. A partir desse mapeamento, as áreas de estudos foram divididas em quadrantes, e foram traçadas linhas imaginárias para facilitar a localização do lote de animais de cada sistema.

A exploração da área pelos animais foi observada pelo período de 12 horas, com início às seis horas e término às 18 horas, do dia 31 de agosto de 2015. Não houve precipitação pluviométrica no dia da observação, e as temperaturas mínima, média e máxima foram $17,6,26,8$ e $36,0^{\circ} \mathrm{C}$, respectivamente.

Em cada sistema avaliado, havia um observador treinado, que permanecia no piquete, em um local onde não era possível interferir no comportamento dos animais, sempre respeitando a distância de fuga deles. Com a utilização do mapa do piquete, o observador registrava o local de permanência do lote de animais a cada 10 minutos. A cada intervalo de 10 minutos, foi designada uma numeração referente ao local no qual o lote de animais se encontrava concentrado, sendo às seis horas referente ao número 1 e às 18 horas referente ao número 73 .
No momento da avaliação, era indicada, no mapa, pelo avaliador, a numeração referente ao horário de observação e ao local em que os animais estavam no piquete.

Concluída a observação de campo, a sequência numérica foi inserida nos mapas utilizando-se as ferramentas de imagem do pacote Office (Microsoft, 1995), em que se pôde encontrar o caminho percorrido pelos animais (Fig. 1). O intervalo de 12 horas de observação foi dividido em três períodos: das seis às 10 horas $(\boldsymbol{\Delta})$; das $10 \mathrm{~h} 10$ às $14 \mathrm{~h}(\bullet)$ e das $14 \mathrm{~h} 10$ às $18 \mathrm{~h}(\mathbf{\square})$.

O deslocamento dos animais no sistema ILP durante a avaliação foi maior que nos sistemas ILPFs, resultando em maior exploração da área disponível (Fig. 1). Isso ocorreu pela presença das árvores, pois, para os animais, assemelharam-se a cercas, limitando a exploração do piquete nos ILPFs. No ILPF-2, pela maior densidade de árvores, esse comportamento ficou mais evidente (Fig. 1), sendo o deslocamento dos animais mais intenso entre os renques de árvore. Outro ponto que deve ser levantado é que não foi realizada a desrama nos ILPFs, assim os galhos aumentaram ainda mais as limitações ao campo visual dos animais.

No primeiro período de observação (Fig. 1), os animais do sistema ILP se locomoveram de forma acentuada, em desnível, cortando sete curvas de nível. Já os animais nos sistemas ILPFs, independentemente da densidade de árvores, mantiveram-se no limite final do piquete, próximos às cercas, sem alterar o local em que se encontravam desde o início da observação. Santana (2017), em estudo do comportamento de bovinos da raça Nelore na mesma área experimental, observou que animais nos sistemas ILPFs sentiram-se menos protegidos, pois apresentaram maior período na posição em pé quando comparados aos animais do sistema ILP, em razão de apresentarem um campo de visão menos amplo, permitindo-lhes menor controle sobre sua distância de fuga. O mesmo fato pode ter ocorrido no início da manhã no presente estudo: os animais sentiram-se menos protegidos pela menor intensidade de luz, aliada à presença das árvores, o que dificultou a visualização do horizonte de pastejo, limitando a movimentação dos animais nas primeiras horas da manhã. 

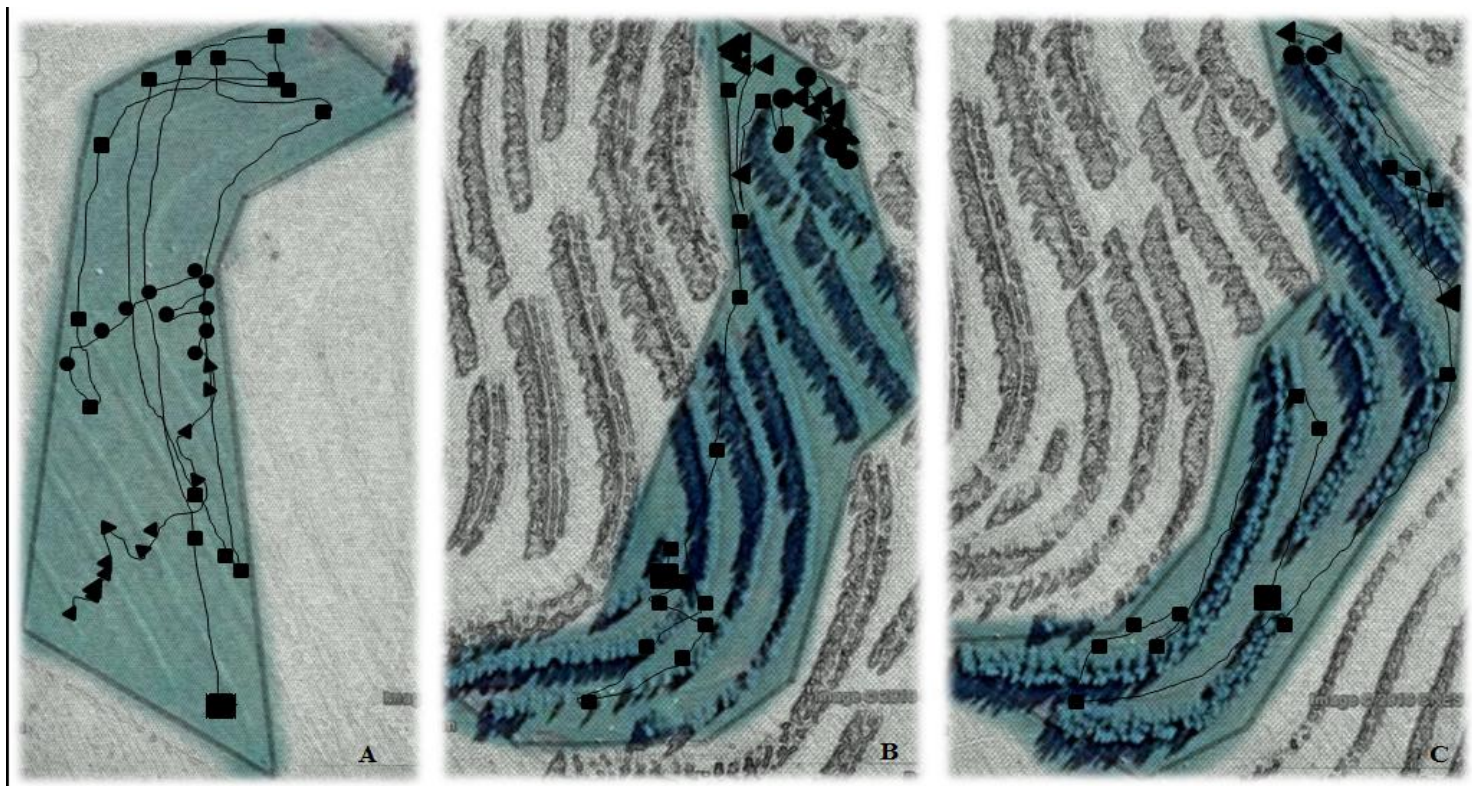

Figura 1. Representação esquemática do deslocamento de bovinos Nelore em sistemas integrados de produção agropecuária. A) Integração lavoura-pecuária; B) lavoura pecuária-floresta, na densidade de 196 árvores.ha ${ }^{-1}$ e C) integração lavoura-pecuária-floresta, na densidade de 448 árvores.ha $^{-1}$. Intervalo das seis às 10 horas $(\mathbf{A})$; das 10 h10 às $14 \mathrm{~h}(\bullet)$ e das $14 \mathrm{~h} 10$ às $18 \mathrm{~h}(\mathbf{\square})$.

No segundo período (Fig. 1), o caminho percorrido pelos animais foi reduzido em comparação ao período anterior, em todos os sistemas, embora tenha sido mais acentuado no sistema ILP. As temperaturas mais elevadas nesse intervalo $\left(18,48 ; 31,66\right.$ e $31,06^{\circ} \mathrm{C}$ para $\boldsymbol{\Lambda}$, - e $\mathbf{n}$, respectivamente) fizeram com que a movimentação dos animais fosse reduzida, de forma a diminuir o ganho de calor pela atividade muscular (Glaser, 2003).

No terceiro período (Fig. 1), a movimentação de animais foi observada em maior escala em todos os tratamentos, sendo percorridas, pelos animais, maiores áreas que os demais períodos. Provavelmente, esse comportamento ocorreu devido à redução da temperatura ambiente e à necessidade dos animais em consumirem água e suplemento mineral, fazendo com que se empenhassem mais no deslocamento em direção ao bebedouro e ao cocho de sal, localizados na extremidade oposta ao local de preferência dos lotes nos sistemas com árvores.

Entre as características da pastagem (Tab. 1), numericamente, a MST foi a que apresentou maior distância nos resultados encontrados entre os tratamentos, sendo maior no sistema ILP e menor no sistema ILPF-2. Castro (2002) afirma que, em situações com abundância de forragem, o número de passos entre estações alimentares é alto, na medida em que o animal colhe uma massa de bocado elevada na estação anterior, o que permite a ele caminhar entre estações por mais tempo enquanto mastiga e resulta em maior exploração da área de pastejo, podendo este ser outro motivo de os animais que estavam no ILP se deslocarem com maior intensidade em comparação aos ILPFs.

As observações realizadas neste estudo indicam que o deslocamento de bovinos em SIPA é influenciado pela presença e densidade de componente arbóreo, condições ambientais e características da pastagem. Fazem-se necessários novos estudos para obter informações sobre a influência do conforto térmico promovido pelas árvores, a interferência da desrama de eucaliptos, a disposição e densidade dos renques de árvores no padrão de deslocamento e o comportamento dos bovinos de corte em SIPA, a fim de otimizar o uso das áreas de pastejo e o bem-estar animal.

Palavras-chave: comportamento de gado, condicionador de pastagem, eucalipto, integração de pecuária-floresta 


\begin{abstract}
The objective of this study was to characterize the displacement patterns of Nellore cattle in areas of crop livestock and crop livestock forest integration systems with density of 196 and 448 eucalyptus ha-1. Paddock maps were drawn from satellite images of the experimental area. In each evaluated system there was one trained observer, that on the paddock map recorded the place the animals stayed every 10 minutes. The exploration of the area by the animals was observed for 12 hours, starting at 6 a.m. and ending at 6 p.m. The displacement of the animals in the ILP system during the evaluation was bigger than the ILPFs systems, resulting in greater exploration of the area, this fact was due the presence of trees that, for the animals resembled fences, limiting the exploration of the paddock in ILPFs. In the ILPF with higher density of trees, this behavior was more evident. In the period from 10:10 a.m. to 14:00 p.m. the displacement of the animals was decrease by the high temperatures in all systems, although it was more effective in the ILP system. It is concluded that the displacement of cattle is influenced by the presence and density of arboreal component integrated crop livestock system.
\end{abstract}

Keywords: grazing conditioner, cattle behavior, eucalyptus, crop-livestock-forest integration

\section{REFERÊNCIAS}

BALBINO, L.C.; CORDEIRO, L.A.M.; OLIVEIRA, P. et al. Agricultura sustentável por meio da integração lavoura-pecuária-floresta (iLPF). Inf. Agron., v.138, p.1-18, 2012.

BALBINO, L.C.; CORDEIRO, L.A.M.; PORFÍRIO-DA-SILVA, V. et al. Evolução tecnológica e arranjos produtivos de sistemas de integração lavoura-pecuária-floresta no Brasil. Pesqui. Agropecu. Bras., v.46, p.i-xii, 2011.

CASTRO, C.R.C. Relações planta-animal em pastagem de milheto (Pennisteum americanum (L.) Leeke.) manejada em diferentes alturas com ovinos. 2002. 200f. Dissertação (Mestrado em Zootecnia) - Faculdade de Agronomia, Universidade Federal do Rio Grande do Sul, RS.

GLASER, F.D. Aspectos comportamentais de bovinos da raça angus a pasto frente à disponibilidade de rescurso de sombra e água para imersão. 2003. 84f. Dissertação (Mestrado em Zootecnia) - Faculdade de Zootecnia e Engenharia de Alimentos, Universidade de São Paulo, Pirassununga, SP.

MICROSOFT Project for Windows 95. Version 4.1. [S.L.]: Microsoft Corporation, 1995. 1 CDROM.
MOTT, G.O.; LUCAS, H.L. The design, conduct, and interpretation of grazing trials on cultivated and improved pastures. In: INTERNATIONAL GRASSLAND CONGRESS, 6., 1952, State College. Proceedings... State College: State Coilege Presa, 1952.

NAVARINI, F.C.; KLOSOWSKI, E.S.; CAMPOS, A.T. et al. Conforto térmico de bovinos da raça nelore a pasto sob diferentes condições de sombreamento e a pleno sol. Eng. Agríc., v.29, p.508-517, 2009.

OLIVEIRA, V.S.; FAGUNDES, J.L.; SANTANA NETO, J.A. et al. Comportamento ingestivo diurno de bovinos em sistema silvipastoril na região do Sertão Sergipano. Rev. Cient. Prod. Anim., v.13, p.1-6, 2011.

SANTANA, E.A.R. Composição morfológica e valor alimentício de capim- marandu $e$ comportamento de bovinos nelore em sistemas integrados de produção agropecuária. 2017. 108f. Tese (Doutorado em Zootecnia) Faculdade de Medicina Veterinária e Zootecnia, Universidade Estadual Paulista, Botucatu, SP.

SOUZA, W.; BARBOSA, O.R.; MARQUES, J.A. et al. Microclimate in silvipastoral systems with eucalyptus in rank with different heights. Rev. Bras. Zootec., v.39, p.685-694, 2010. 